\title{
A Novel Hybrid Control Strategy of a STATCOM for Power Quality Improvement in a Grid Connected Wind Energy System
}

\author{
Ketha Vamsikrishna ${ }^{1}$, K.Sainadh Singh ${ }^{2}$, Dr. B. Venkata Prasanth ${ }^{3}$ \\ ${ }^{1}$ P.G Scholar, QIS College of Engineering \& Technology, Ongole, JNTU Kakinada, India \\ ${ }^{2}$ Assistant Professor, Department of EEE QIS College of Engineering \& Technology, Ongole, JNTU Kakinada, India \\ ${ }^{3}$ Professor \& Head of the Department of EEE, QIS College of Engineering \& Technology, Ongole, JNTU Kakinada, India
}

\begin{abstract}
By means of the increase in demand for electricity due to increase in population industrialization, the generation of power is really a challenge now a days. It is essential to meet the energy needs by utilizing the renewable energy resources like wind, biomass, hydro co-generation, etc. Addition of the wind power into an electric grid affects the power quality. The major power quality issues are voltage sag, swell, flickers, harmonics etc. During this future scheme Static Compensator (STATCOM) is linked at the point of common coupling with a battery energy storage system to mitigate the power quality issues. The battery energy storage is integrated to sustain the real power source under fluctuating wind power. Here three control schemes for STATCOM are compared: PI controller, fuzzy logic controller and Hybrid controller. The process of the three STATCOM control schemes for maintaining the power quality of the grid connected wind energy system is investigated using MATLAB/SIMULINK.
\end{abstract}

Keywords: STATCOM, power quality, wind generating system, battery energy storage system (BESS), pi controller fuzzy logic controller, hybrid controller and MATLAB.

\section{Introduction}

In cooperation of electric utilities and end users of electric power are increasingly worried about the quality of power. Power quality can be defined as "any power problem manifested in voltage, current and frequency those results in failure or mal operation of the customer equipment" [1]. Addition of the wind power into an electric grid affects the power quality. [2]

The assembly of devices used for improvement of power quality problems is known by the name of Custom Power Devices (CPDs). The family of compensating devices mainly has the following members: Static Synchronous Compensator (STATCOM), Dynamic Voltage Restorer (DVR) and Unified Power Quality Conditioner (UPQC). The occupation analyses the presentation of Static Compensator (STATCOM) with a battery energy storage system (BESS) connected at the point of common coupling of wind energy generating system and the obtainable power system to alleviate the power quality issues. [1]

Throughout the normal operation, wind turbine produces a incessant variable output power. The most important power quality issues are voltage sag, swell, flickers, harmonics etc [3]. One of the straightforward methods of running a wind generating system is to use the induction generator connected directly to the grid. The induction generator has inherent advantages of cost efficiency and heftiness. But, induction generators require reactive power designed for magnetization.

After the generated active power of an induction generator is varied due to wind, absorbed reactive power and terminal voltage of an induction generator can be considerably affected. At this time proposing a STATCOM based control technology for mitigating the power quality issues when we are integrating wind farms to the grid.

During the event of increasing grid disturbance, a battery energy storage system is required to compensate the fluctuation generated by wind turbine. Here three control schemes for STATCOM is designed and compared: BangBang current controller, fuzzy logic controller HPF controller is used.

\section{Topology for Power Quality Improvement}

The STATCOM is a three- phase voltage source inverter having the capacitance on its DC link and connected at the point of common coupling. The STATCOM injects a compensating current of variable magnitude and frequency component at the bus of common coupling. Here the utility source, wind energy system and STATCOM with BESS is connected to the grid. The current controlled voltage source inverter based STATCOM injects the current into the grid in such a way that the source current (grid current) are harmonic free and they are in phase-angle with respect to source voltage. The injected current will cancel out the reactive part and harmonic part of the induction generator current and load current, hence it improves the power quality. This injected current generation is by proper closing and opening of the switches of voltage source inverter of STATCOM and is different for the two control schemes proposed. For this the grid voltages are sensed and are synchronized in generating the current command for the inverter. 


\section{International Journal of Science and Research (IJSR) \\ ISSN (Online): 2319-7064}

Index Copernicus Value (2013): 6.14 | Impact Factor (2014): 5.611

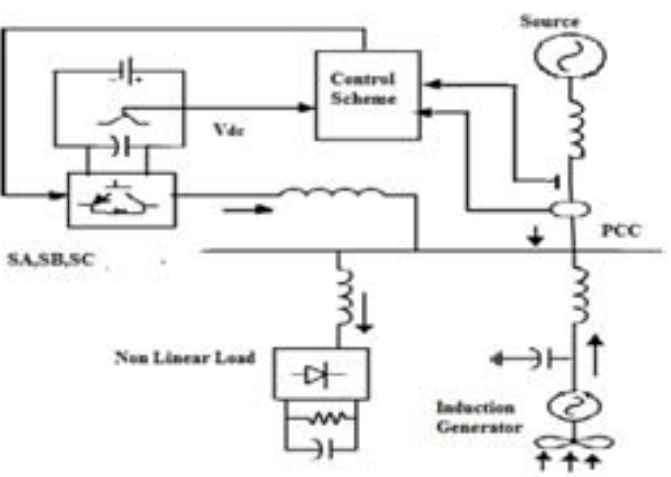

Figure 1: System operational scheme in grid system

The induction generator is used in the proposed scheme because of its simplicity, it does not require a separate field circuit, it can accept constant and variable loads, and has natural protection against short circuit. The available power of wind energy system is presented as:

$$
P_{\text {wind }}=\frac{1}{2} \rho A V^{a} \text { wind }
$$

Where $\rho=$ air density $\left(\mathrm{kg} / \mathrm{m}^{3}\right), A=$ area swept out by turbine blade $(\mathrm{m})$, Vwind $=$ wind speed $(\mathrm{m} / \mathrm{s})$.It is not possible to extract all kinetic energy of wind. Thus extracts a fraction of the power called power coefficient „Cp $\mathrm{Cp}^{\text {ee }}$ of the wind turbine, and is given by

$$
P_{\text {mech }}=C_{p} P_{\text {wind }}
$$

The mechanical power produced by wind turbine is given by

$$
P_{\text {mech }}=\frac{1}{2} \rho \pi R^{2} V^{a}{ }_{\text {wind }} C_{\mathrm{p}}
$$

Where, $\mathrm{R}=$ Radius of the blade $(\mathrm{m})$.

\subsection{BESS-STATCOM}

The battery energy storage system (BESS) is used as energy storage element for the purpose of voltage regulation.

The BESS will naturally maintain dc capacitor voltage constant and is best suited in STATCOM since it rapidly injects or absorbs reactive power to stabilize the grid system. When power fluctuation occurs in the system, the BESS is used to level the power fluctuation by charging and discharging operation. The battery is connected in parallel to the dc capacitor of STATCOM.

\subsection{System Operation}

The shunt connected STATCOM with battery energy storage is connected at the interface of the induction generator and non-linear load at the PCC [4]. The Fig.1 represents the system operational scheme in grid system. The STATCOM output is varied according to the control strategy, so as to maintain the power quality norms in the grid system. The current control strategies for STATCOM are the Bang-Bang controller and fuzzy logic controller. A single STATCOM using insulated gate bipolar transistors is proposed to have a reactive power support to the induction generator and to the nonlinear load in the grid system.

\subsection{Control Scheme}

The first control scheme approach is based on injecting the currents into the grid using "bang-bang controller" [1].The controller uses a hysteresis current controlled technique as shown in Fig 3. Using such a technique, the controller keeps the control system variable between the boundaries of hysteresis area and gives correct switching signals for STATCOM operation. The current controller block receives reference current and actual current as inputs and are subtracted so as to activate the operation of STATCOM in current control mode [5]. The second control scheme is fuzzy logic controller. The inputs to the controller, ,change in grid voltage $(\Delta \mathrm{V})^{\mathrm{ee}}$ and change in grid current $(\Delta \mathrm{I})^{\mathrm{ee}}$ and is represented as membership functions of the controller.The output is correct switching signals for IGBTs of STATCOM $(\Delta \mathrm{U})$

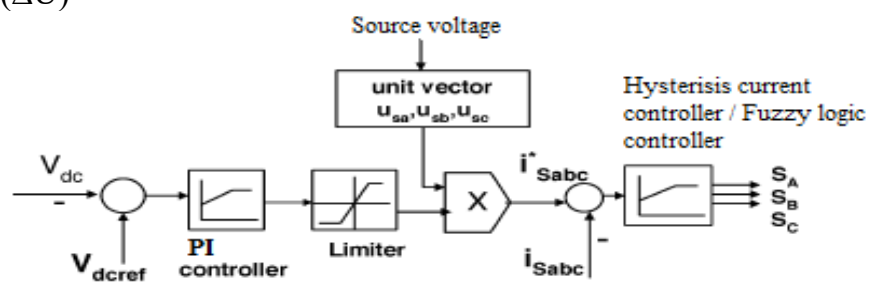

Figure 2: Control system scheme

\subsection{Grid synchronization}

In three-phase balance system, the RMS voltage source amplitude is calculated at the sampling frequency from the source phase voltage $\left(\mathrm{V}_{\mathrm{sa}} \mathrm{V}_{\mathrm{sb}} \mathrm{V}_{\mathrm{sc}}\right)$ and is expressed, as sample template $\mathrm{V}_{\mathrm{sm}}$ sampled peak voltage, as in(4).

$$
V_{s m}=\left\{\frac{2}{3}\left(V_{s a}^{2}+V_{s b}^{2}+V_{s c}^{2}\right)\right\}^{\frac{1}{2}}
$$

The in-phase unit vectors are obtained from AC source-phase Voltage and the RMS value of unit vectors are shown in (5).

$$
u_{s a}=\frac{V_{s a}}{V_{s m}}, u_{s b}=\frac{V_{s b}}{V_{s m}}, u_{s c}=\frac{V_{s c}}{V_{s m}}
$$

The in-phase generated reference current share derived using in-phase unit voltage template as, in(6).

$I_{s a}^{s}=I . u_{s a}, I_{s b}^{s}=I \cdot u_{s b}, I_{s c}^{*}=I . u_{s c}$.

Where, I is proportional to magnitude of the filtered source voltage for respective phases. This ensures that the source current is controlled to be sinusoidal. The unit vectors implement the important function in the grid connection for the synchronization for STATCOM. This method is simple, robust and favorable as compared with other methods.

\section{Wind Energy in the Power System}

Wind is a continuously varying source of energy and so is the active power generated by the wind turbine. If a Wind Turbine is connected to a grid the terminal voltage also fluctuates, producing flicker, harmonics and inter-harmonics due to the presence of power electronics. For a set of connected wind turbines forming a wind farm, the ree exit certain grid codes or specific requirements with which each wind turbine must conform with in order to be allowed to be connected to the grid. Most wind power systems are based in remote rural locations and are therefore prone to voltage sags, faults, and unbalances. These unbalanced grid voltages can cause many problems such as torque pulsations, unbalanced currents and reactive power pulsations [6].

\section{Volume 4 Issue 11, November 2015}




\section{International Journal of Science and Research (IJSR) \\ ISSN (Online): 2319-7064 \\ Index Copernicus Value (2013): 6.14 | Impact Factor (2014): 5.611}

When wind farms are connected to a strong grid, that is closer to a stiff source, voltage end frequency can be quickly re-established after a disturbance with the support of the power grid it self. To wait for the voltage tore-establish after the fault has been cleared in the case of a weak grid interconnection is not reliable because there is always a risk of voltage instability initiated by the disturbance. Hence, reactive power and voltage support that can be provided by mechanically switched capacitors, SVC or STATCOM is needed to help improve the short term voltage stability and reinforce the power network. This is also true for wind farms with all fixed speed wind turbines with no dynamic control or reactive power compensation. [7]

There are many wind turbine manufacturers who produce different wind turbine technologies. Table1 gives a list of all the MW range Wind Turbines manufactured by various producers and their technical specifications

Table 1: States wise wind installed capacity

\begin{tabular}{|l|c|}
\hline \multicolumn{1}{|c|}{ State } & Capacity (MW) \\
\hline Andhra Pradesh & 471.45 \\
\hline Gujarat & 3196.58 \\
\hline Karnataka & 2148.9 \\
\hline Kerala & 54.8 \\
\hline Madhya Pradesh & 395 \\
\hline Maharashtra & 3107.45 \\
\hline Rajasthan & 2721.2 \\
\hline Tamil Nadu & 7162.88 \\
\hline West Bengal & 1.1 \\
\hline Others & 572.64 \\
\hline Total & 19832 \\
\hline
\end{tabular}

\subsection{Fixed Speed Wind Turbine}

A Fixed-speed wind turbine system (FSWT) is a simpler way of connecting wind power on to the electric grid. Today, such a system uses an induction machine almost exclusively for converting the mechanic power extracted from wind into electric power.

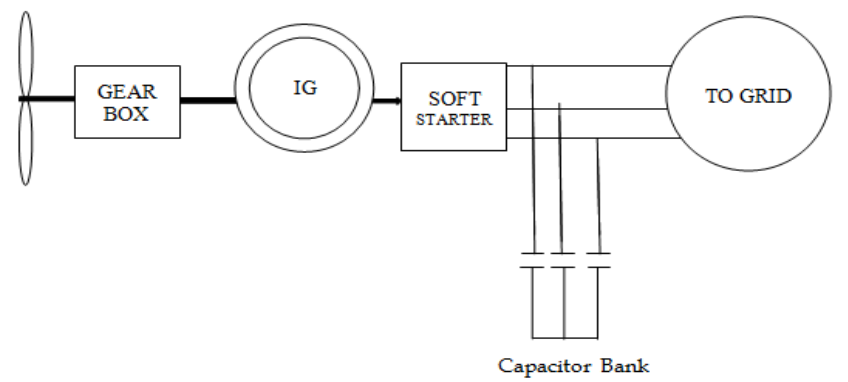

Figure 3: Fixed speed wind turbine

With reference to Figure3, apart from the turbine and the induction machine, a fixed-speed system incorporates a gearbox. This is because the rotational speed of the turbine is always lower than the generator speed. An economically feasible multi pole induction machine design applicable to wind power applications has not been found so far. Another common part is the capacitor bank typically designed to compensate for the induction generator no-load reactive power consumption. Finally, a soft starter is a standard part of the system. It is used only during the startup of the turbine and it lowers the current when the turbine is being connected to the grid. A wind turbine without a soft starter would draw a very high current during start up and the corresponding voltage drop in the grid would exceed the stated limits. Moreover, the gearbox would suffer from transient torques.

\subsection{Variable Speed Wind Turbine}

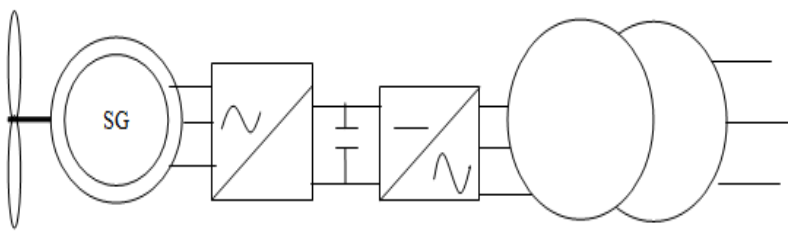

Figure 4: Variable-speed direct-driven (gear-less) wind turbine with a synchronous generator

The system presented in Fig4 consists of a wind turbine equipped with a converter connected to the stator of generator. The generator could either be a cage-bar induction generator or a synchronous generator. The gearbox is designed so that maximum rotor speed corresponds to rated speed of the generator. Synchronous generators or permanent-magnet synchronous generators can be designed with multiple poles which imply that there is no need for gearbox. One advantage with this system is its welldeveloped and robust control. [9]

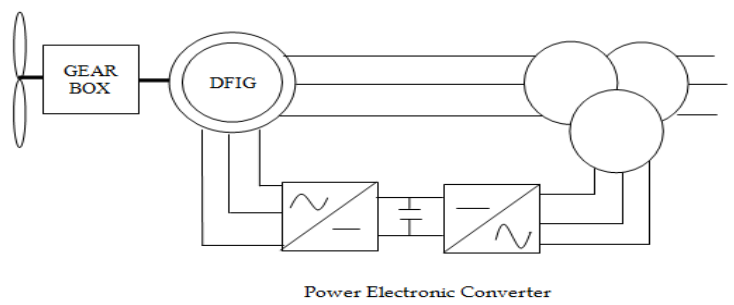

Figure 5: Variable-speed wind turbine with a doubly-fed induction generator (DFIG)

The system, see Fig5 consists of a wind turbine with doublyfed induction generator. This means that the stator is directly connected to the grid while the rotor winding is connected via slip rings to a converter. This system has recently become very power electronic converter only has a handle a fraction $(20-30 \%)$ of the total power. Therefore, the losses in the converter have to be reduced, compared to a system where the converter has to handle the total power. In addition, the cost of the converter becomes lower. There exists a variant of the DFIG method that uses controllable external rotor resistances (compare to slip power recovery). Some of the drawback of this method are that energy is unnecessary dissipated in the external rotor resistances and that is not possible to control the reactive power.

Of all the above mentioned types we are going to use the first type because of its simplicity that is fixed speed wind turbine method with induction generator. Due to the advantages that we considered in real time application and also in Simulink designing we adopted the induction generator.

\section{Volume 4 Issue 11, November 2015}




\section{International Journal of Science and Research (IJSR) \\ ISSN (Online): 2319-7064}

Index Copernicus Value (2013): 6.14 $\mid$ Impact Factor (2014): 5.611

\subsection{SVC/STATCOM/UPFC Comparisions}

The thyristor protected series compensation (TPSC), thyristor Controlled series compensation(TCSC) are those FACTS devices that have a strong influence on the system stability and small or no influence on the voltage quality. The SVC and STATCOM have a strong influence on voltage quality improvement and show medium performance with respect to were all the system stability. The unified power flow controllers (UPFC) have shown efficient performance in terms of load flow support, stability and voltage equality. The main objective in this is to look for solutions to provide voltage stability to the system in order to operate wind turbines in a coordance with the grid codes. The STATCOM is the best option available for providing efficient voltage quality in the power system.

A STATCOM is a shunt-connected reactive power compensation device that is capable of generating and/or absorbing reactive power and in which the output can be varied to control the specific parameter so fan electric power system. The STATCOM is a static compensator and is used to regulate voltage and to improve dynamic stability [11]. A STATCOM can supply the required reactive power under various operating conditions, to control the network voltage actively and thus, improve the steady state stability of the network. The STATCOM can be operated over its full output current range even at very low voltage level sand the maximum var generation or absorption changes linearly with the utility or ac system voltage.

The maximum compensating current of the SVC decreases linearly with the ac system voltage end the maximum var output decreases with the square of the voltage. This implies that for the same dynamic performance, a higher rating SVC is required when compared to that of a STATCOM. For an SVC, the maximum transient capacitive current is determined by the size of the capacitor and the magnitude of the ac system voltage. In the case of a STATCOM, the maximum transient capacitive over current capability is determined by the maximum turn-off capability of the power semiconductors employed.

Figure4 shows the schematic of SVC and its VI characteristics. Figure6 shows the schematic of the STATCOM and its VI characteristics. The main function of a STATCOM is to provide reactive power support and thus improve voltage stability. The main objective of using a UPFC in a system is to be able to control both active and reactive power in the associated line in which it is placed. The STATCOM has better reactive power control than an SVC as seen in Figures 4 and5.

Mechanically switched capacitors do not have a better performance at lower voltages and hence a higher rating device is needed for the same performance. Also, the reactive power support provided by the SVC is dependent on the ac system voltage and hence its capability is de-rated at lower voltages. The UPFC is not very economical and requires more complicated control techniques for exploiting its complete capabilities.

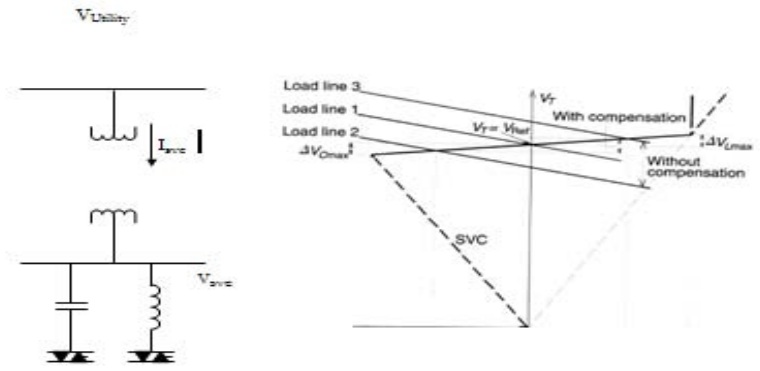

Figure 6: SVC and its VI characteristics $\mathrm{v}_{\mathrm{tan}=\mathrm{T}}$
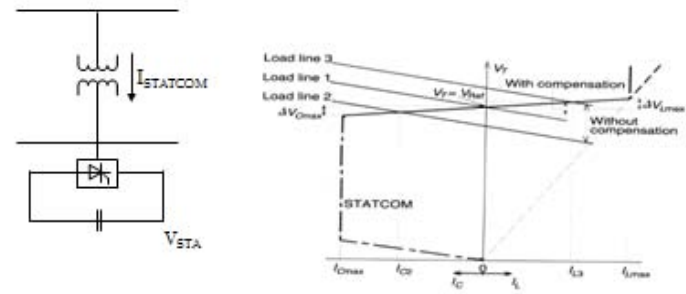

Figure 7: STATCOM and its VI characteristics

\section{System Parameters}

Table 2: System parameters

\begin{tabular}{|c|c|c|}
\hline S.No & Parameters & Ratings \\
\hline 1. & Grid voltage & 3Phase, $415 \mathrm{~V}, 50 \mathrm{~Hz}$ \\
\hline 2. & $\begin{array}{l}\text { Induction } \\
\text { Motor/Generator }\end{array}$ & $\begin{array}{l}12 \mathrm{KVA}, 415 \mathrm{~V}, 50 \mathrm{~Hz}, \\
\mathrm{Speed}=1440 \mathrm{rpm}, \mathrm{Rs}=0.005 \Omega \\
\mathrm{Rr}=0.0005 \Omega, \mathrm{Ls}=0.125 \mathrm{H}, \\
\mathrm{Lr}=0.18 \mathrm{H}\end{array}$ \\
\hline 3. & Line series Inductance & $6.37 \mathrm{Mh}$ \\
\hline 4. & Inverter Parameters & $\begin{array}{l}\text { DC link voltage }=800 \mathrm{~V} \\
\text { DC link capacitance }=600 \mathrm{Mf} \\
\text { Switching frequency }=2 \mathrm{KHz}\end{array}$ \\
\hline 5. & Load parameter & Non linear load 25KW \\
\hline 6. & Wind turbine & $\begin{array}{l}\text { Base wind speed }=11 \mathrm{~m} / \mathrm{s} \text { Pitch } \\
\text { angle }(\beta)={ }^{\circ e} 0^{\circ} \mathrm{deg}\end{array}$ \\
\hline
\end{tabular}

\section{Controllers}

Here three control techniques are used

1. PI Controller

2. Fuzzy logic controller and

3. HPF Controller

\subsection{PI Controller}

For the generation of reference signal DC link voltage is measured and compared with the reference values by means of a PI controller. The output of the PI controller is multiplied with the unit vectors. Hence we will get reference currents.

\subsection{Fuzzy Logic Controller}

Fuzzy set theory provides an excellent means for representing uncertainty due to Vagueness in the available data or unknown behavior of a system. It can represent the human control processes and also allows experimental knowledge in adjusting the controller parameters. 


\section{International Journal of Science and Research (IJSR) \\ ISSN (Online): 2319-7064}

Index Copernicus Value (2013): 6.14 | Impact Factor (2014): 5.611

\subsection{Fuzzy Sets}

A fuzzy set is a collection of distinct elements with a varying degree of relevance or inclusion. If $\mathrm{X}$ is a set of elements, then a fuzzy set $\mathrm{A}$ in $\mathrm{X}$ is defined to be a set of ordered pairs, $A=\{(x, \mu A(x)) x \in X\}$ where $\mu A(x)$ is called the membership function of $\mathrm{x}$ in $\mathrm{A}$. This membership function can take $\mu A$ $(x)$ denotes the degree to which $\mathrm{x}$ belongs to $\mathrm{A}$ and is normally limited to values between 0 and 1.A high value of $\mu$ $A(x)$ implies that it is very likely for $\mathrm{x}$ to be in $\mathrm{A}$.

\subsection{Fuzzy If - Then rules}

Table 3: Fuzzy If-Then rules

\begin{tabular}{|l|l|l|l|l|l|l|l|}
\hline$\Delta \mathrm{V}$ & & & & & & & \\
\hline NB & NB & NB & NB & NB & NM & NS & ZE \\
\hline NM & NB & NB & NM & NM & NS & ZE & PS \\
\hline NS & NB & NM & NS & NS & ZE & PS & PM \\
\hline ZE & NM & NM & NS & ZE & PS & PM & PB \\
\hline PS & NM & NS & ZE & PS & PS & PM & PB \\
\hline PM & NS & ZE & PS & PM & PM & PB & PB \\
\hline PB & ZE & PS & PM & PB & PB & PB & PB \\
\hline
\end{tabular}

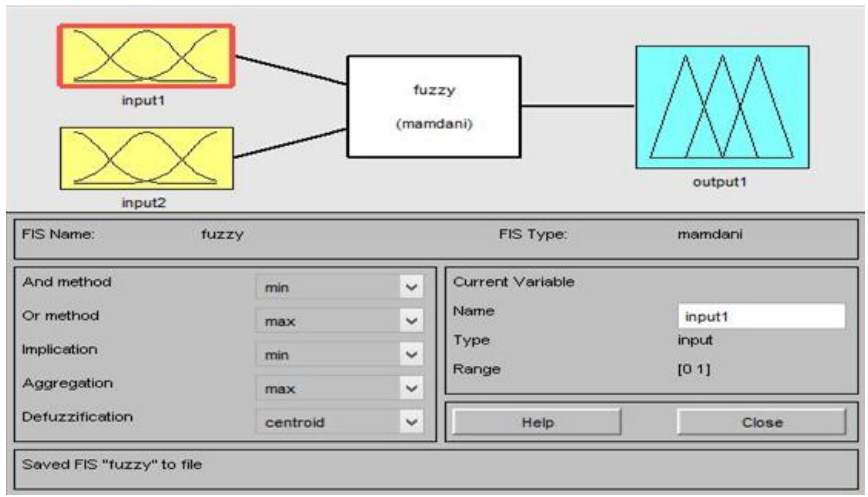

Figure 8: Two inputs fuzzy logic controller

In the fuzzy model the knowledge relating the input features and the output class are represented by the fuzzy if - then rules of the form $R_{j}$ : if $x_{p l}$ is $A_{j l}$ and $x_{p n}$ is $A_{j n}$, then class $C_{j}$ with $C F=C F_{j}$ where $A_{j 1}, \ldots A_{j n}$ are antecedent fuzzy sets in the unit interval $[0,1], \mathrm{C}_{\mathrm{j}}$ is one of the class codes and $\mathrm{CF}_{\mathrm{j}}$ is the grade of certainty of the rule. A collection of such statements replace the usual mathematical model of system theory. The knowledge required to generate the fuzzy if then rules can be derived from an expert operator and a design engineer or by an off - line simulation.

In this paper, fuzzy control is used to control the firing angle for the switches of the VSI of STATCOM. In this design, the fuzzy logic based STATCOM has two inputs, ,change in voltage $(\Delta \mathrm{V})^{\text {ee }}$ and ,change in current $(\Delta \mathrm{I})^{\text {ee }}$ and one control $\operatorname{output}(\Delta \mathrm{U})$

Firstly the input values will be converting to fuzzy variables. This is called fuzzification. After this, fuzzy inputs enter to rule base or interface engine and the outputs are sent to defuzzification to calculate the final outputs. These processes are demonstrated in Fig 9.
Here seven fuzzy subsets have been used for two inputs. These are: PB (positive big), PM (positive medium), PS (positive small), ZE (zero), NS (negative small), NM (negative medium) and NB (negative big). We use Gaussian membership functions [8] and 49 control rules are developed, which are shown in table 3.

Fuzzification: It is the process of representing the inputs as suitable linguistic variables .It is first block of controller and it converts each piece of input data to a degree of membership function. It matches the input data with conditions of rules and determines how well the particular input matches the conditions of each rule.

Defuzzification: The output of a fuzzy rule based system is generally imprecise and fuzzy. As a fuzzy set cannot directly be used to take the decisions, the fuzzy conclusions of rule based systems have to be converted in to precise quantity. This is called Defuzzification. There are various methods like centroid method, weighted average method and maxmembership method etc... for this purpose.

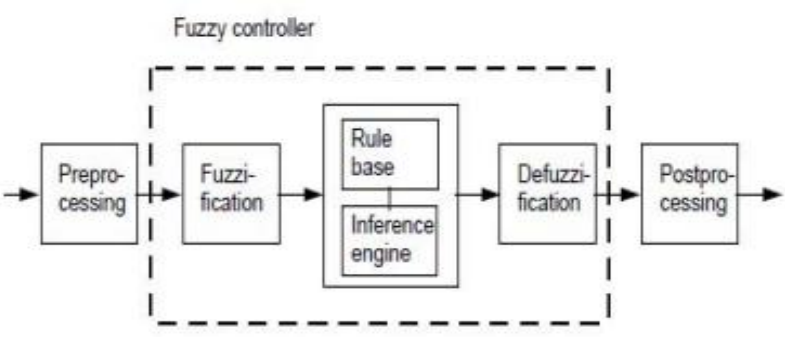

Figure 9: Fuzzy control block diagram
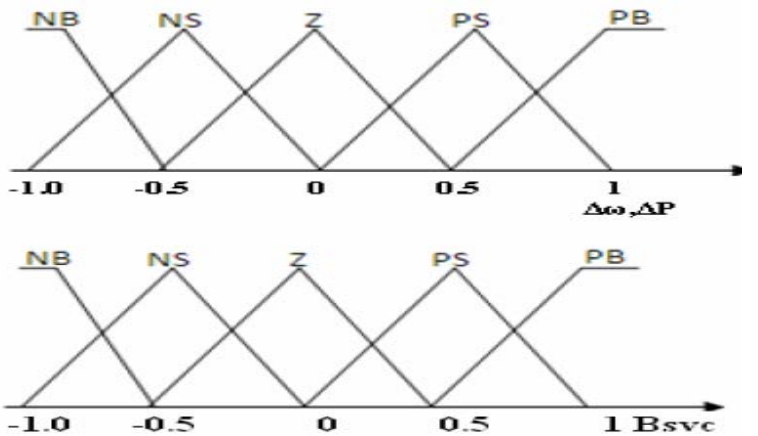

Figure 10: Membership functions of $\Delta \omega, \Delta \mathrm{P}$ and Bsvc

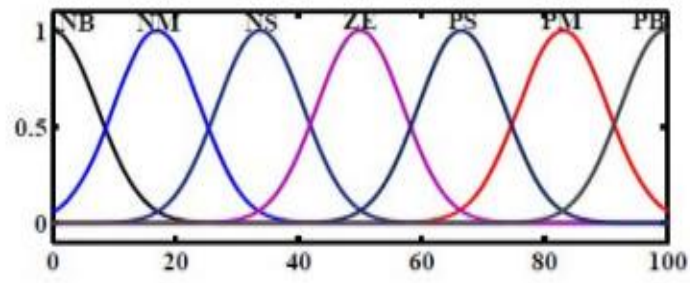

Figure 11: Membership function of $\Delta I$

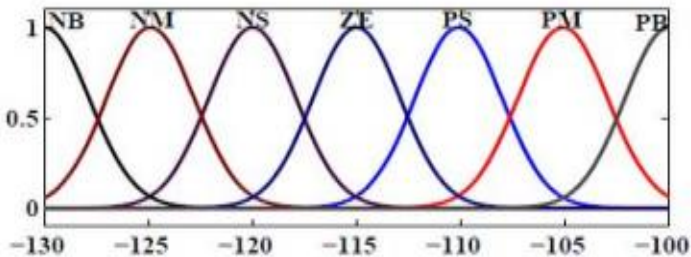

Figure 12: Membership function of $\Delta V$ 


\section{International Journal of Science and Research (IJSR) \\ ISSN (Online): 2319-7064}

Index Copernicus Value (2013): 6.14 $\mid$ Impact Factor (2014): 5.611

\subsection{HPF Controller}

Here in this project a novel controller i.e. Hybrid PI with fuzzy logic controller has been introduced. Such that it can takes both advantages of PI controller and HPF controller. The schematic diagram of a SVC along with Fuzzy logic based damping controller. Generator speed deviation ( $\omega)$ and $(\Delta P)$ are taken as the input signals of the fuzzy controller.

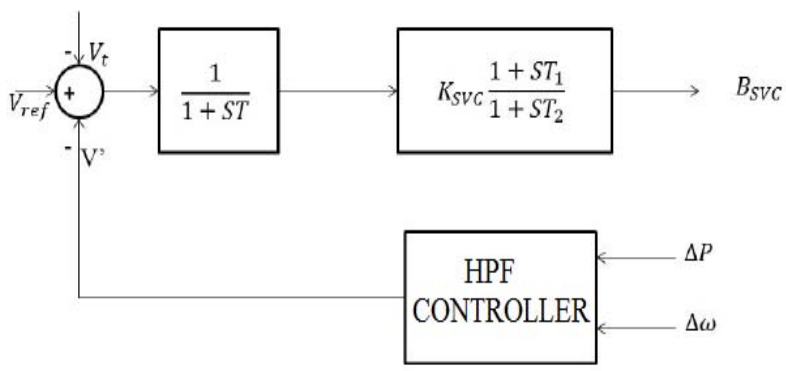

Figure 13: Block of proposed HPF controller diagram

The number of member ship functions for each variable determines the quality of control which can be achieved using fuzzy logic controllers In the present investigation, five membership functions are defined for the input and output variables.Fig. 3 shows the membership functions defined. The mentioned member ship functions are used to specify a set of rules called a rule base. The rules developed are based on the knowledge and experience. With two inputs and five linguistic terms, 25rules were developed which is given inTable1. In inference mechanical small the rules are compared to the inputs to determine which rules apply to the current situation. After the matching process the required rules are fired. The controlled output Bsve is determined for the different input conditions. The defuzzification produces the final crisp output of HPF with the fuzzified input. Centroid method is employed where the output will be calculated as in eqn(7).

$$
O / P=\frac{\sum_{i=1}^{5} b_{i} \int \mu_{(i)}}{\sum_{i=1}^{5} \int \mu_{(i)}}
$$

\section{Simulation Results}

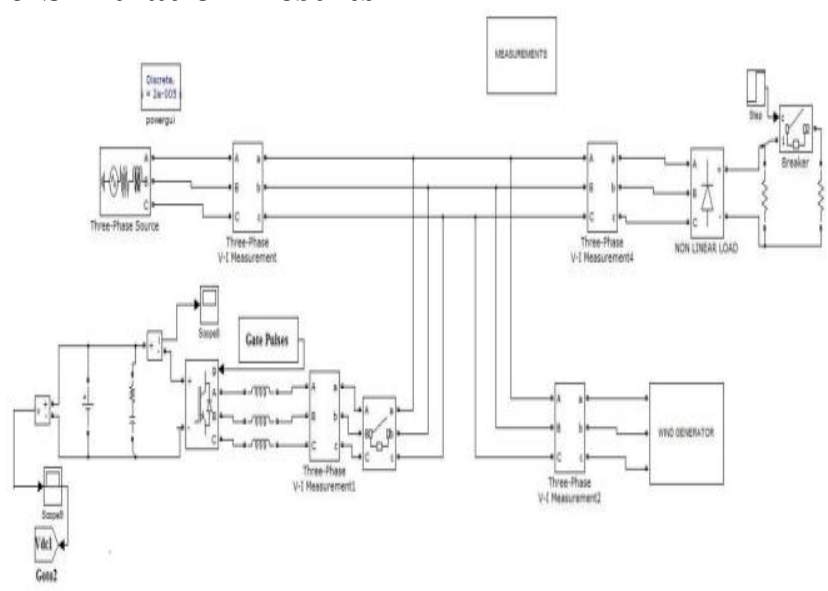

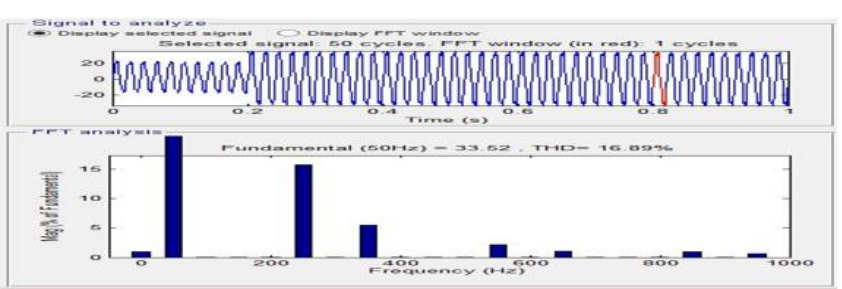

Figure 15: THD value of without STATCOM

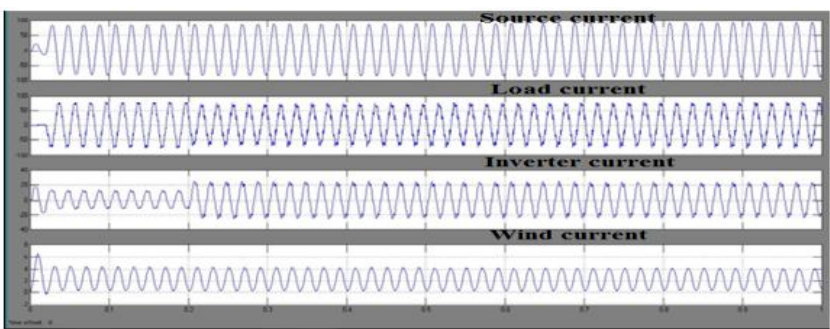

Figure 16: Simulation results of PI controller

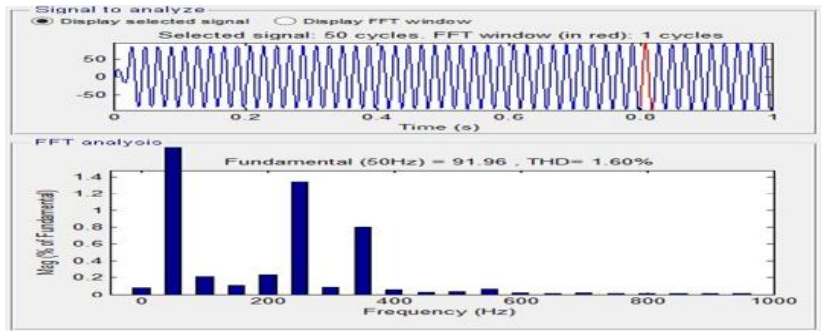

Figure17: THD value of source PI controller

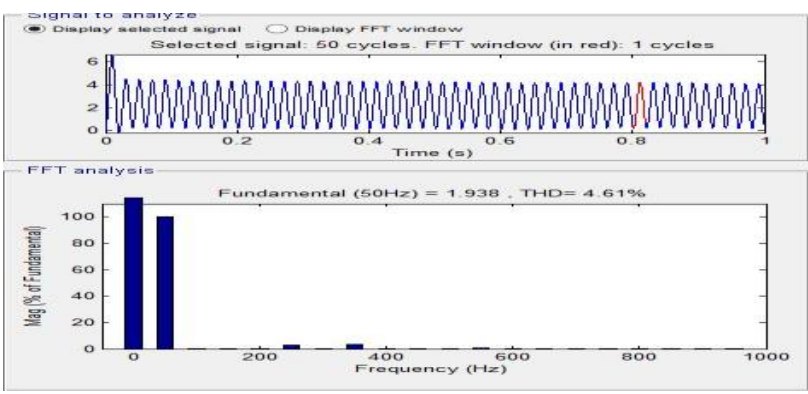

Figure18: THD value of wind PI controller

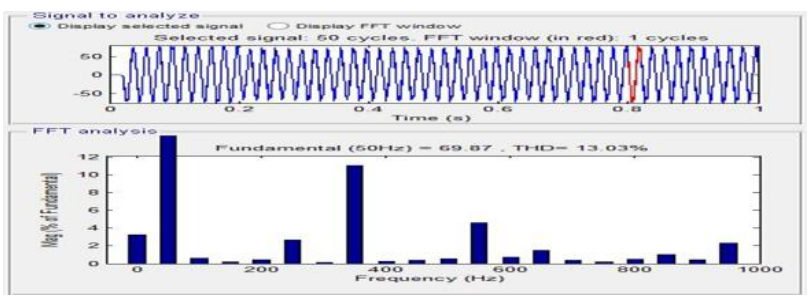

Figure 19: THD value of load PI controller

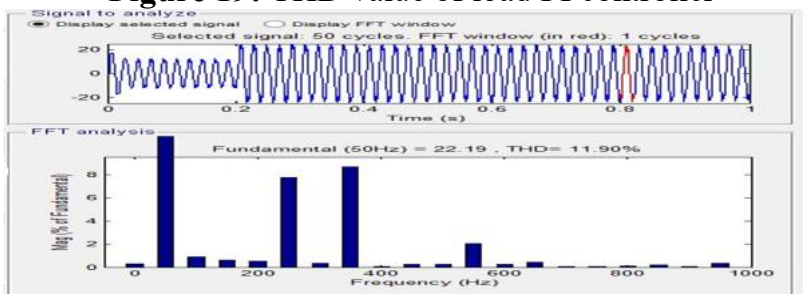

Figure 20: THD value of inverter PI controller

Figure 14: SIMULINK diagram 


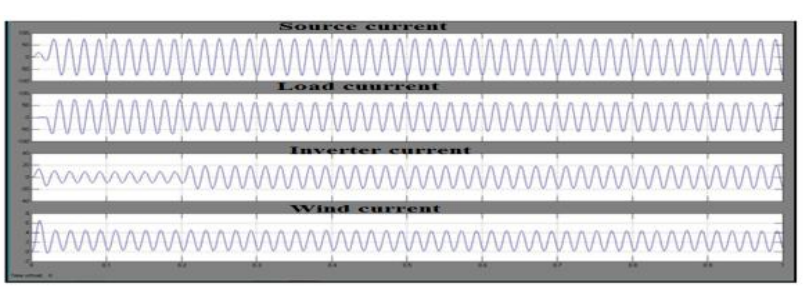

Figure 21: Simulation results of fuzzy logic controller

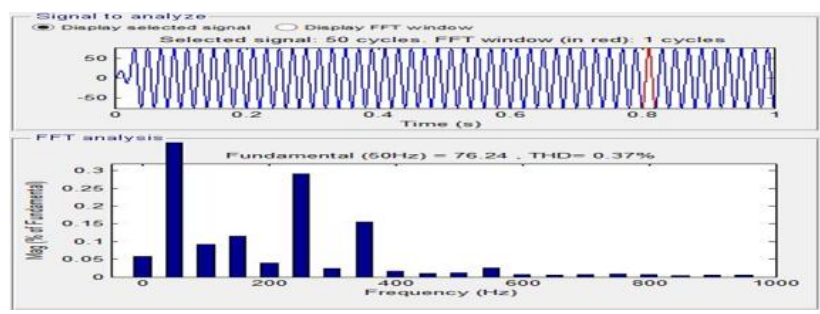

Figure 22: THD value of source fuzzy logic controller

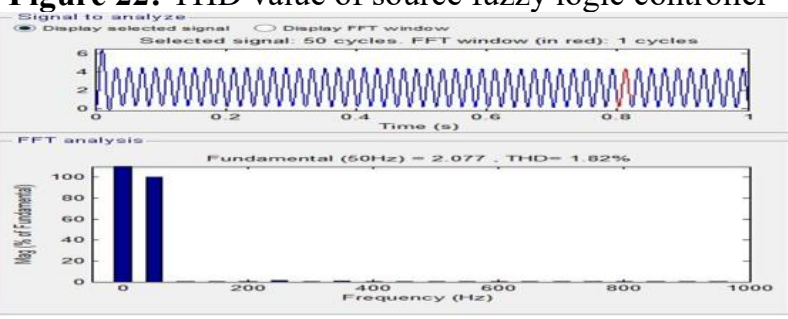

Figure 23: THD value of wind fuzzy logic controller

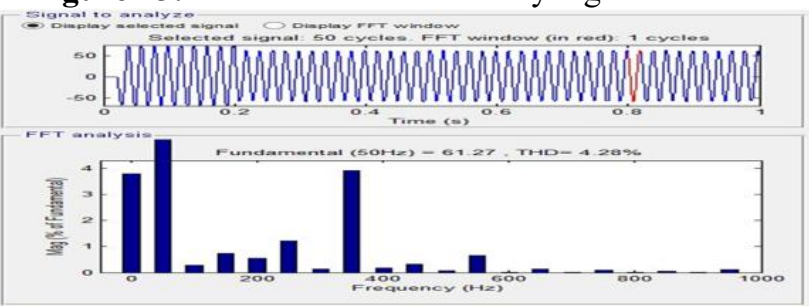

Figure 24: THD value of load fuzzy logic controller

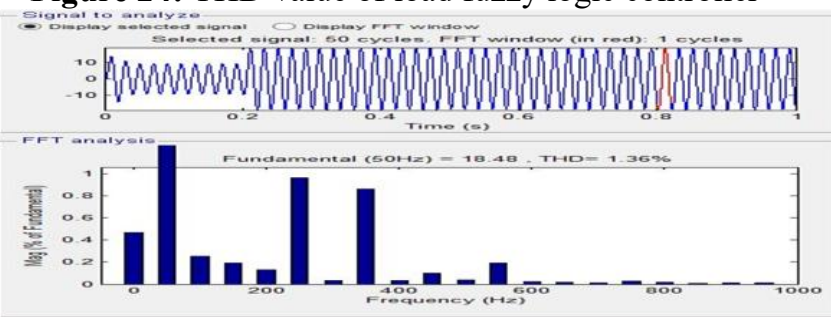

Figure 25: THD value of inverter fuzzy logic controller

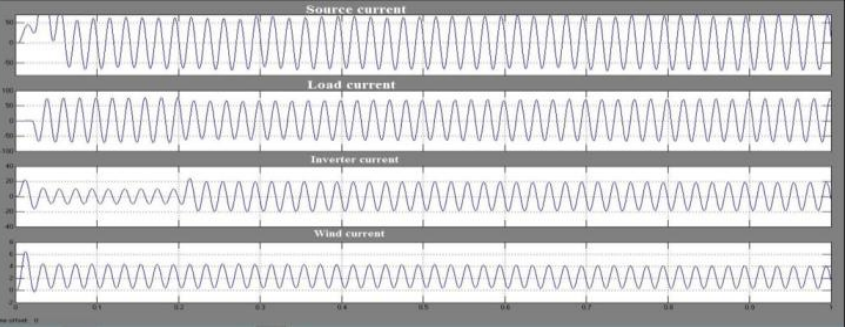

Figure 26: Simulation results of HPF controller

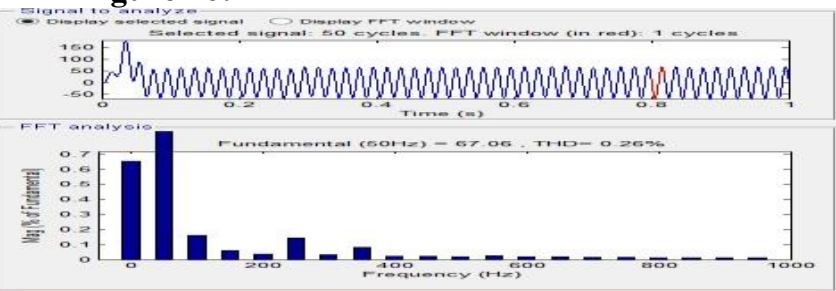

Figure27: THD value of source HPF controller

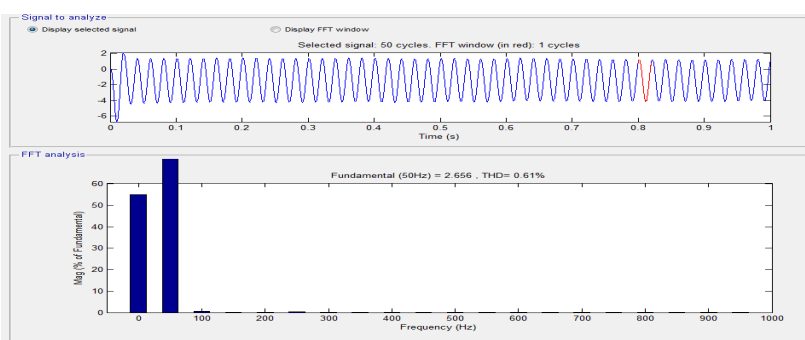

Figure 28: THD value of wind HPF controller

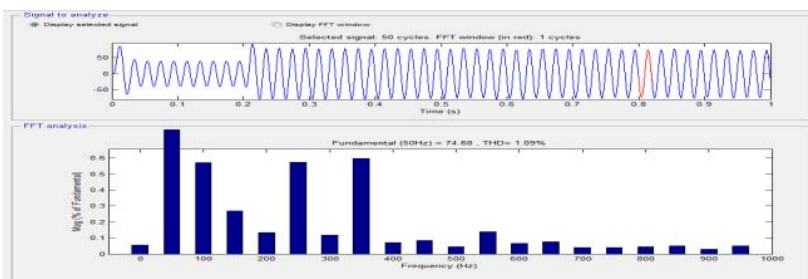

Figure 29: THD value of load HPF controller

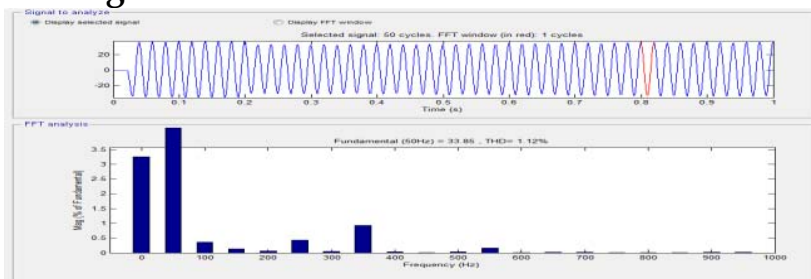

Figure 30: THD value of inverter HPF controller

Table 4: All parameters values of THD

\begin{tabular}{|c|l|l|l|l|}
\hline & $\begin{array}{l}\text { Source } \\
\text { Curren } \\
\mathrm{t}\end{array}$ & $\begin{array}{l}\text { Wind } \\
\text { Current }\end{array}$ & $\begin{array}{l}\text { Load } \\
\text { Current }\end{array}$ & $\begin{array}{l}\text { Inverter } \\
\text { Current }\end{array}$ \\
\hline PI Controller & $1.60 \%$ & $4.61 \%$ & $11.90 \%$ & $13.03 \%$ \\
\hline $\begin{array}{l}\text { Fuzzy Logic } \\
\text { Controller }\end{array}$ & $0.37 \%$ & $1.82 \%$ & $4.28 \%$ & $1.36 \%$ \\
\hline $\begin{array}{c}\text { HPF } \\
\text { Controller }\end{array}$ & $0.26 \%$ & $0.61 \%$ & $1.09 \%$ & $1.12 \%$ \\
\hline
\end{tabular}

\section{Conclusion}

This paper presents the STATCOM-based control scheme for power quality improvement in grid connected wind generating system with non linear loads.

The operation of the STATCOM is simulated using three controllers: PI controller, Fuzzy logic controller and HPF controller. STATCOM injects current to the grid and it cancel out the reactive and harmonic parts of the induction generator current and load current. When we are reducing the wind generating system output, it will not affect the source current magnitude.

The THD analysis revealed that the HPF controller is good compared to PI controller. The fuzzy logic controller is simpler and has faster response. The integrated wind generation.

\section{References}

[1] Sharad W. Mohod, Mohan V. Aware "A STATCOM control scheme for grid connected wind energy system

\section{Volume 4 Issue 11, November 2015}




\section{International Journal of Science and Research (IJSR) \\ ISSN (Online): 2319-7064}

Index Copernicus Value (2013): 6.14 | Impact Factor (2014): 5.611

for power quality improvement" IEEE SYSTEMS JOURNAL, VOL. 4, NO. 3, SEPTEMBER 2010.

[2] C. Han, A. Q. Huang, M. Baran, S. Bhattacharya, and W. Litzenberger, "STATCOM impact study on the integration of a large wind farm into a weak loop power system," IEEE Trans. Energy Conv., vol. 23, no. 1,pp. 226-232, Mar. 2008.

[3] M. I. Milands, E. R. Cadavai, and F. B. Gonzalez, "Comparison of control strategies for shunt active power filters in three phase four wire system," IEEE Trans. Power Electron., vol. 22, no. 1, pp. 229-236, Jan. 2007.

[4] Sharad W. Mohod, Member, IEEE, and Mohan V. Aware "Micro wind power generator with battery storage" IEEE SYSTEMS JOURNAL, VOL. 6, NO. 1, MARCH 2012.

[5] S. W. Mohod and M. V. Aware, "Power quality issues \& it's mitigation technique in wind energy conversion," in Proc. of IEEE Int. Conf. Quality Power \& Harmonic, Wollongong, Australia, 2008.

[6] J. J. Gutierrez, J. Ruiz, L. Leturiondo, and A. Lazkano, "Flicker measurement system for wind turbine certification," IEEE Trans. Instrum. Meas., vol. 58, no. 2, pp. 375-382, Feb. 2009

[7] S. Sabna, D. Prasad, R. Shivakumar,"Power System Stability Enhancement by Neuro Fuzzy Logic Based SVC for Multi Machine System”, IJEAT, ISSN: 2249 8958, Volume-1, Issue-4, April 2012.

[8] N. Karpagam , D.Devaraj, "Fuzzy Logic Control of Static Var Compensator for Power System oscillations Damping'International Journal of Electrical and Electronics Engineering, October 2009.

[9] T.Kinjo and T. Senjyu, "Output levelling of renewable energy by electric double layer capacitor applied for energy storage system," IEEE Trans. Energy Conv., vol. 21, no. 1, Mar. 2006.

[10] R.S.Bhatia, S. P. Jain, D. K. Jain, and B. Singh, "Battery energy storage system for power conditioning of renewable energy sources," in Proc. Int. Conf. Power Electron Drives System, Jan. 2006, vol. 1, pp. 501-506.

[11] S. Sabna, D. Prasad, R. Shivakumar, "Power System Stability Enhancement by Neuro Fuzzy Logic Based SVC for Multi Machine System”IJEAT, ISSN: $2249-$ 8958, Volume-1, Issue-4, April 2012.

\section{Author Profile}

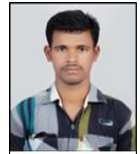

Ketha Vamsikrishna is obtained B.Tech degree in Electrical and Electronics Engineering from the Sri Satyanarayana Engineering college, JNTU Kakinada in 2012. He Pursuing M.Tech in Power Electronics and Power System from QIS college of Engineering \& Techology, JNTU Kakinada Andhra Pradesh, India . His areas of interests include Power Electronics in Research Industrical Sectrors.

K. Sainadh Singh obtained B.Tech degree in Electrical and Electronics Engineering from the St Anns college of Engineering and Technology, JNTU Kakinada in 2011. He completed M.E degree in Power Systems and Automation from Sir CR Reddy Engineering college, Andhra University, Andhra Pradesh, India in 2014. His areas of interests include power System Operation and Control, Control System, optimization, Renewable energy systems power quality. He had several International and Nationl conferences, Journals.

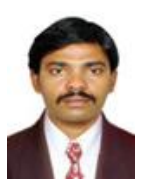

Dr. B. Venkata Prasanth received the B.Tech. degree in Electrical \& Electronics Engineering from Sri Krishnadevaraya University \& M.Tech. degree in Electrical Power Systems from Jawaharlal Nehru Technological University, Ananthapur, India. He received his Ph.D. degree in Electrical \& Electronics Engineering from Jawaharlal Nehru Technological University, Hyderabad, India. He has got a teaching experience of more than 14 years. Currently, he is working as Professor \& Head in QIS College of Engineering and Technology, Ongole, India in the Dept. of Electrical \& Electronics Engineering. He has published a number of papers in various national \& international journals \& conferences. He is also guiding a number of research scholars in various topics of electrical engineering. His research interests include application of intelligent controllers to power system control design, power system restructuring, power system economics \& optimization. 